\title{
How the analysis of transitionary references in knowledge networks and their centrality characteristics helps in understanding the genesis of growing technology areas
} DOI:

10.1007/s11192-017-2340-z

\section{Document Version \\ Accepted author manuscript}

Link to publication record in Manchester Research Explorer

Citation for published version (APA):

Kadyrova, A., \& Fursov, K. (2017). How the analysis of transitionary references in knowledge networks and their centrality characteristics helps in understanding the genesis of growing technology areas. Scientometrics, 111(3), 1947-1963. https://doi.org/10.1007/s11192-017-2340-z

\section{Published in:}

Scientometrics

\section{Citing this paper}

Please note that where the full-text provided on Manchester Research Explorer is the Author Accepted Manuscript or Proof version this may differ from the final Published version. If citing, it is advised that you check and use the publisher's definitive version.

\section{General rights}

Copyright and moral rights for the publications made accessible in the Research Explorer are retained by the authors and/or other copyright owners and it is a condition of accessing publications that users recognise and abide by the legal requirements associated with these rights.

\section{Takedown policy}

If you believe that this document breaches copyright please refer to the University of Manchester's Takedown Procedures [http://man.ac.uk/04Y6Bo] or contact uml.scholarlycommunications@manchester.ac.uk providing relevant details, so we can investigate your claim.

\section{OPEN ACCESS}


Fursov, K. \& Kadyrova, A. (2017), How the analysis of transitionary references in knowledge networks and their centrality characteristics helps in understanding the genesis of growing technology areas. Scientometrics, DOI 10.1007/s11192-017-2340-z

\title{
HOW THE ANALYSIS OF TRANSITIONARY REFERENCES IN KNOWLEDGE NETWORKS AND THEIR CENTRALITY CHARACTERISTICS HELPS IN UNDERSTANDING THE GENESIS OF GROWING TECHNOLOGY AREAS
}

\author{
Konstantin Fursov ${ }^{1}$ and Alina Kadyrova ${ }^{2}$ \\ ${ }^{1}$ Institute for Statistical Studies and Economics of Knowledge, National Research University \\ Higher School of Economics, Moscow, Russia \\ ksfursov@hse.ru \\ ${ }^{2}$ Institute for Statistical Studies and Economics of Knowledge, National Research University \\ Higher School of Economics, Moscow, Russia \\ akadyrova@hse.ru
}

\begin{abstract}
Since early 1960s, there has been a growing interest in the emergence and development of new technologies accompanied by a strong wish from decision makers to govern related processes at the corporate and national levels. One of the key categories that appeared to set up analytical and regulatory frameworks was the 'advanced technology' category. Primarily associated with computer electronics and microelectronics, it soon had new meanings derived from a variety of professional discussions primarily in the social sciences. Later in a new term, 'emerging technologies', appeared to highlight the speed of change in a wide range of promising research areas. This paper focuses on the evolution of academic discussions concerning advanced and emerging technologies in social sciences literature for the period from 1955 until 2015. In order to identify whether studies in these areas constitute separate research fields, the paper studies the evolution of co-citation networks and the centrality characteristics of transitionary references. It was shown that social studies in emerging technologies demonstrate better consistency in background in literature. However, an analysis of transitionary references and their centrality characteristics can hardly confirm the existence of separate research fields in both cases. The suggested method for the identification and tracking of papers mediating ongoing discussions in a selected knowledge network may be helpful in understanding the evolution of weakly conceptualized and growing research areas.
\end{abstract}

Keywords Advanced technology, emerging technology, graph analysis, bibliometric analysis, co-citation, betweenness centrality. 


\section{INTRODUCTION}

Technological development is the main driver of international competitiveness and economic growth. Therefore, technological progress has become a policy priority for many countries, and considerable financial resources are invested with the expectation of long- and short-term returns. Since the 1950s interest in the development and use of new technologies has steadily grown, together with the attempts of decision makers to regulate related processes at the institutional and national levels. To describe the ongoing changes in global technological development, a selected number of terms emerged to tag similar groups of technologies (Manyika et al., 2013; SEC, 2009; OECD, 2013). The most popular labels are emerging, disruptive, enabling and advanced technologies. These terms are also widely used in the academic literature (Fig.1) and provide relevant classification categories (e.g., see Gokhberg et al., 2013) or elaborate an operational definition (Halaweh, 2013; Rotolo et al., 2015) to clarify the meaning a widely used umbrella concept.

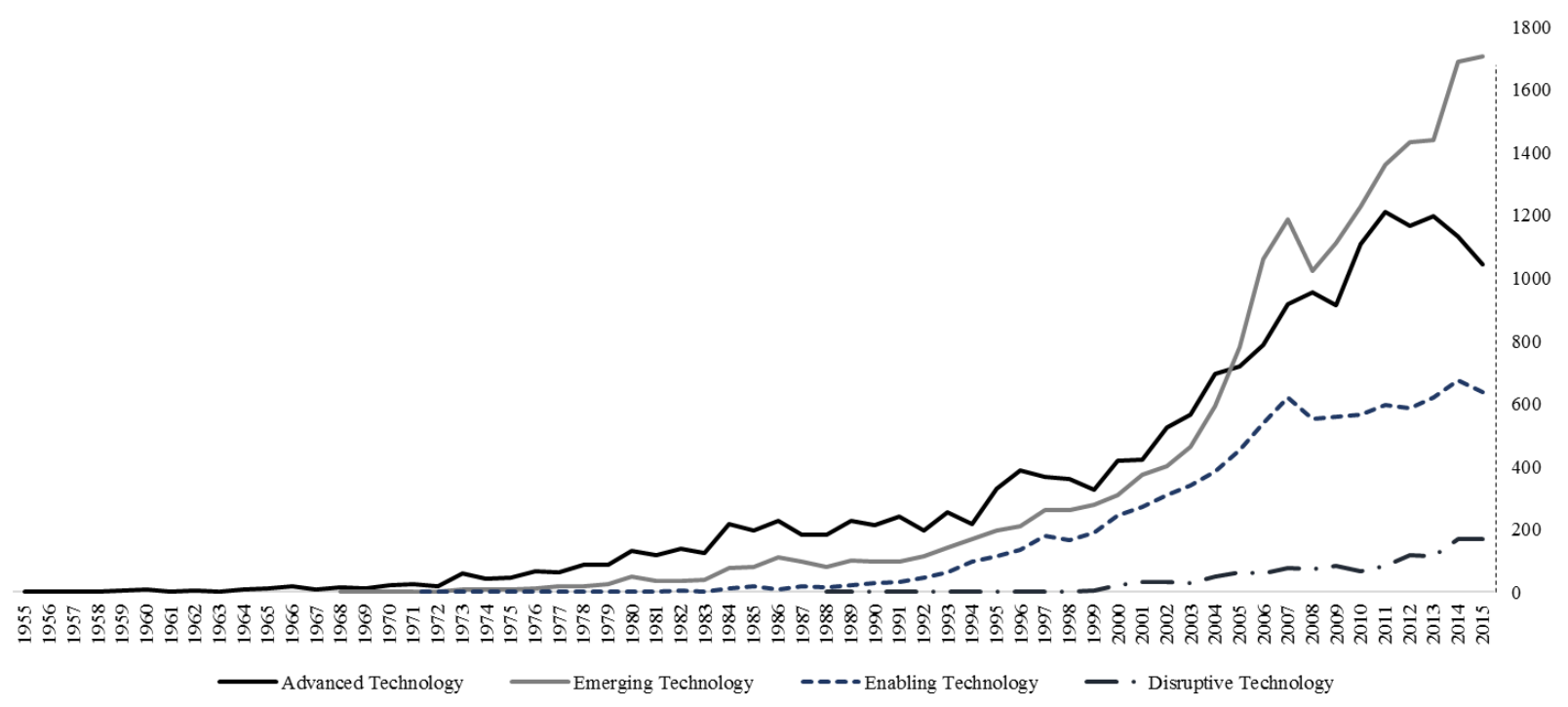

Fig. 1. Number of documents in SCOPUS that include terms 'advanced technology', 'emerging technology', 'enabling technology' and 'disruptive technology' in title, abstract or keywords.

Time span: $1955-2015$.

Among the four mentioned technological categories, two deserve special attention, namely the 'advanced' and 'emerging' technologies. The former is broader and older, comprising various technologies from flexible manufacturing, computer-aided design to robotics and automated storage systems. The term appeared in the literature in the 1950s and became the foundation for the future development of other types of technologies.

Advanced technology is a key category that emerged together with a set of definitions and distinct criteria for R\&D. Immediately following WWII, advanced technologies were primarily associated with the growing need for sufficient training of technical specialists (Venables, 1962). Early definitions of the term addressed various features of advanced technologies. Before 1980s it implied a certain complexity of production processes, including the required equipment and organizational methods, with the aim to increase efficiency (Solo, 1966). Advanced technologies were embedded in discussions of developments in energy storage (Robinson, 1974), automation processes and computer utilization (Scott, 1973). Later definitions used the term primarily in 
controlling, tracking or monitoring related manufacturing processes (Youssef, 1992; Boyer, et al., 1997).

The mid 1990s were marked by the first conventional definition of advanced technology, which was proposed in the Frascati Manual in relation to manufacturing processes (OECD, 1994) and the occurrence of the term in statistical and other surveys (Baldwin \& Da Pont, 1996; Baldwin \& Sabourin, 2002). Despite the growing interest in the role of advanced technology in economic growth, the definition vanishes from later editions of the Manual as well as from other OECD manuals. The term seemed to contradict the dominant term relating to the measurements and evaluation of technology. Still, the definition proposed in the Manual was replicated in some later works (e.g. Dangayach \& Deshmukh, 2004).

Despite the variety of interpretations, there still is no common understanding or a notion of advanced technologies. There are however some common features that the majority of authors share: novelty, relation to information technology, and improvement in efficiency of current operation or production processes. However, in the literature one can hardly find robust criteria for distinguishing advanced technology from others. Moreover, some of the characteristics used in the definitions such as novelty or efficiency, are universal and therefore relevant for the definitions of other groups of technologies.

As opposed to the vague concept of 'advanced technology', the literature on emerging technology is more coherent. Numerous papers present a definition of the concept of 'emergence' in general and 'emerging technology' in particular. The first appearance of 'emerging technology' is associated with the late 1960s. The two early studies using the term belong to different research areas - psychometry and engineering. Despite this fact, both authors perceive 'emerging' as 'new and superior' to existing practices (Wernimont \& Campbell, 1968; Ault, 1968). Later studies equate emergence with uncertainty of outcomes, unobvious social impact or limitations of availability (Halaweh, 2013). One of the recent studies review defining emerging technologies (Rotolo et al., 2015) include five features of emerging technologies: radical novelty, fast growth, coherence, prominent impact, uncertainty and ambiguity.

Since the 1990s, emerging technologies received much attention from scholars in the field of both strategic management and science and technology policy setting. Due to potential of these technologies for discontinuous and pervasive change, particular attention has been paid to their role in socio-economic development. Emerging technologies such as spin transistors, gene therapy, digital imaging, micro-machines are referred as originators of new industries (Hung \& Chu, 2006), with an influence on a country's capability to introduce technological innovations and, therefore, compete at the international level (Porter, et al., 2002). Moreover, the concept has been examined by technological foresight studies to identify the most promising technologies for the socio-economic development of different countries (see e.g. Martin, 1995).

Over time perceptions of certain technological categories have undergone remarkable change in the professional discourse. This paper is focusing on a meta-analysis of discussions on emerging technologies as they are represented in journal articles and asks whether social studies in advanced and emerging technology construct consistent research fields. While conventional approaches focus on the analysis of terminology usage and (re)construction of definitions in order to provide certain conceptual framing of a growing area this study suggests looking at corps of texts that set up a research agenda for a certain period. If a semantically connected group of papers appear once in a network and demonstrate a certain level of stability over time we can conclude 
that there is a self-generating communication core in professional discussions and therefore a consistent research field exists. To identify such a 'communication core' and its elements it is suggested that one take a closer look at reproduction of co-citation networks through analysis of transitionary references. The rise of the same co-cited papers in a longer period can indicate ongoing institutionalization processes in academic discussions. Moreover, it is proposed to look at centrality characteristics of transitionary references to clarify if they are filling gaps in knowledge (i.e. closing structural holes in communication networks) or acting as gatekeepers and consolidating accumulated theoretical or practical experience on a crossroad of different frameworks. Identification of these papers in dynamics may bring a better understanding of the evolution of weakly conceptualized and growing research areas. The overall scheme of the proposed approach is demonstrated at Figure 2.

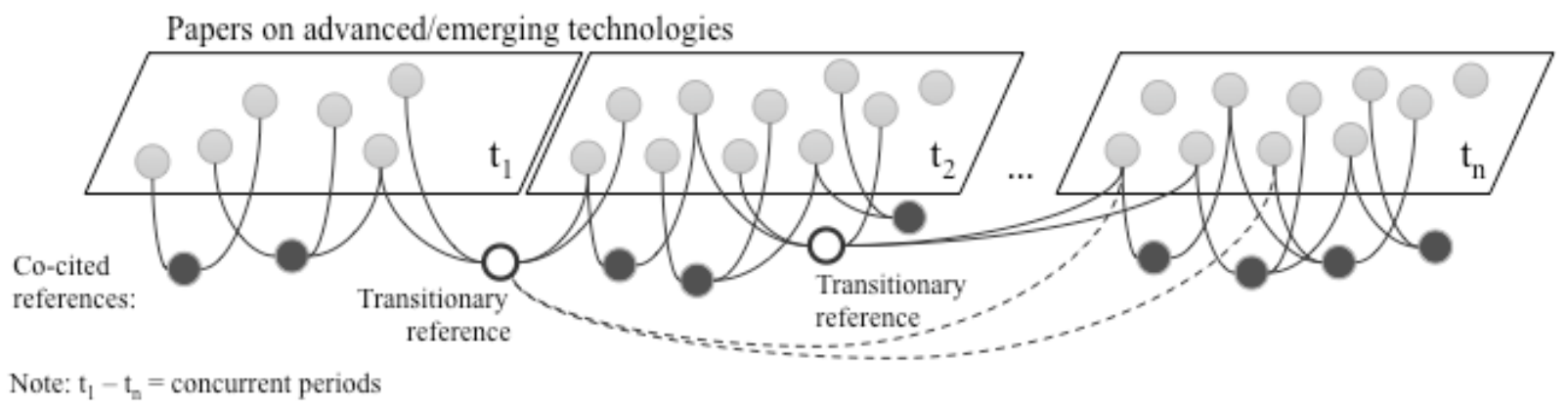

Fig. 2. A proposed approach to analysis of a research field consistency

The paper is structured as follows. First, we address approaches used for the analysis of scientific networks and the identification of a knowledge base in a selected research field or tradition. Here we pay special attention to the idea of spatial configuration of research networks and the notion of 'betweenness centrality'. In the next section, we describe our method in greater detail. In the findings section, the results of our analysis are presented. Finally, we discuss the main findings of the paper and draw conclusions on the limitations of the study and further areas of research.

\section{LITERATURE REVIEW}

Ways to identify the emergence of new scientific and technological areas has recently received great attention from the scientific community (Robinson \& Propp, 2008). Various contributions offer distinctive data mining methods for investigation of the overall dynamics of technology development or growth of specific technology domains. Some scholars suggest looking at bursts of academic publications to detect the emergence of a wider range of technologies (Dernis et al., 2016), while others focus on citation network analysis to identify research fronts in a specific technology domain (Shibata et al., 2011). In these studies authors elaborate their best methods for identification of emerging technologies by modeling milestones [a good review on this can be found in (Abercrombie et al., 2012)], while the question as to whether this area constructs a separate field of research remains untouched. The answer to such a question requires some reflection on theories concerning the social nature of knowledge networks and the evolution of research fields.

Numerous of social studies of science have demonstrated that a research field exists when a group of scholars act within a common paradigm that concentrate their effort on a certain set of cognitive problems (Cole, 1983) and form collective identities, research goals and practices (Whitley, 2000). This approach works properly until one is considering any of the problem- 
oriented fields developed within or against an established standard of research work supported by a certain level of cognitive and social organization of scientific effort (Frickel \& Gross, 2005). In this case, specific patterns of the development of new disciplines and re-organization of scientific fields can be identified through an analysis of organizational change (e.g. see Mullins, 1972, 1973) as well as through the growing interdisciplinarity of science (Porter \& Rafols, 2009). For both cases authors regularly adopt the strategy of exploring the 'knowledge base' of the recognized field by looking at key contributors and/or publications that are setting the research agenda for a certain period (Fagerberg \& Verspagen, 2009; Fagerberg et al., 2012a). In a fewer number of cases authors suggest looking at the emerging knowledge base that is associated with some vague concepts such as 'knowledge economy' (Fagerberg, 2012b). Specific methods of such an analysis may include the identification of keyword combinations, describing the growing research domain (Porter et al., 2008; Wang et al., 2013) or an exploration of the listed number of journals primarily associated with the selected research field (Schummer, 2004). The latter is crucial for the completeness and fullness of an observation as long as the use of some concepts might be a challenge when one is dealing with a weakly defined concept that may have different connotations in different disciplines. One example is the 'knowledge economy' that was mentioned above. Another example is the term 'institution', which despite its common use, has different interpretations in the tradition of classical and new institutionalism used in organizational analysis (DiMaggio \& Powell, 1983; Powell \& DiMaggio, 2012). Therefore, reliance only on methods that search for a common terminology or use of term is not enough to argue for the existence of a research field.

Another strategy to use when considering the development of a scientific field lies in the analysis of communication structures. To identify stable communication networks that feed further academic discussions, scholars suggest using Social Network Analysis (SNA) and particularly co-citation networks (Borgatti et al., 2013). Specifically, attention is paid to the co-citation analysis initially introduced in 1973 for studies of linkages between the documents (Small, 1973; Marshakova-Shaikevich, 1973) to show their semantical relatedness. Further this method was adopted for mapping invisible colleges (Gmür, 1973) and clusters of science (Small, 1999) as well as searching for emerging topics (Small, et al., 2014). As a measure of the frequency with which at least two papers are cited together in other documents, co-citation analysis allows for the identification of cognitively related knowledge clusters accepted (through citations) by a wider network of followers.

Similar ideas can be found in graph theory showing that the spatial configuration of elements might characterize their role in a network. For instance, Bavelas $(1948,1950)$ showed the relationship between centrality and communication processes in small networks. He demonstrated that optimally positioned actors could accumulate information flows from dislocated parts of a network and therefore play a gatekeeping role. Smith (1950) and Leavitt (1951) suggested that authors holding central positions might also influence the behavior of other linked members. For the aim of this study it is assumed that those actors in academic networks that gain more attention from their colleagues through received citations will have a higher social status and therefore hold more central positions (Merton, 1988; Small, 2004). Subsequently, a centrality position would mean the author's association with a communication core of a field.

Recent papers suggest using betweenness centrality algorithms for placing actors and journals in citation networks (Leydesdorff, 2007) to identify core elements of knowledge networks. Papers with higher betweenness are essential in a network as long as they mark parts of the network 
known as 'structural holes', i.e., the separation between non-redundant contacts that provide opportunities for mediating knowledge flows in a wider community of actors (Burt, 2002). On the other hand, betwenness centrality might be taken as a characteristic of gatekeeping papers (Borgatti \& Everett, 2009). While the original theory focuses on competition and social capital in actors' relationship, we took the idea of information flows among actors and further elaborated it for the co-citation networks. In line with Burt, this paper focuses attention on the actors who adopt relatively more important positions and therefore affect co-citation characteristics.

\section{METHOD}

An earlier study by the authors on the evolutionary analysis of advanced technology as a research field showed the penetration of the concept from social sciences to natural and engineering disciplines (Kadyrova and Fursov, 2016). The analysis covered 10-year periods and identified at least three phases with foci on different issues: R\&D and technology management (1991 - 2000), technology diffusion and innovation development $(2001-2010)$, and discussions on specific technologies and materials $(2011-2015)$. The method suggested in the paper was initially adopted from (Yan and Ding, 2009), who investigated co-authorship networks of library and information science through centrality analysis. The authors used different centrality metrics (closeness, betweenness and Page Rank) to compare the stability of positions of the top 30 authors in a network moving from one period to another.

For the aim of this study, it is proposed to use the idea of transitionary papers to a co-citation network in order to identify a communication core in discussions about advanced and emerging technologies. It is assumed that such a core exists when there is an observable, significant number of references moving from one co-citation period to another. In other words, there is an observable and stable citation track that connects discussions in more than one follow-up period. This is expected to be especially relevant for discussions in social sciences as long as they have larger citation windows and longer citation half-life (e.g. se Glanzel, 1996). For a better understanding of the role of transitionary references it is suggested to compare their centrality characteristics of which specific attention is to be paid to betwenness centrality as long as this measure is associated with the idea of gatekeeping in science (Leydesdorff, 2007).

To summarize, in order to verify existence of a separate research field in discussions about advanced and emerging technologies, the following five steps were taken.

\section{Data extraction and the creation of a data set.}

For the purpose of this survey, data was extracted from the SCOPUS database accessed: 20.11.2016 for the period from 1955 until the end of 2015 (all types of documents, social sciences and humanities papers; queries: TITLE-ABS-KEY ("emerging technolog*"), TITLE-ABS-KEY ("advanced technolog*")). This allowed for the extraction of documents using the term explicitly or specific technologies directly associated with it. Papers published in the social sciences and humanities were considered the only data source for the current study. Previous studies showed that the majority of attempts to elaborate a definition or conceptual framework for analysis of vague technology domains came from the social sciences (Rotolo et al., 2015).

2. Identification of periods for comparison.

Using a frequency analysis of the number of documents already reveals several shorter periods of publication activity growth. While the emergence of early papers goes back to 1960s, the 
overall number of studies remains insufficient for the co-citation analysis until mid-1990s for both advanced and emerging technologies (Figure 3).

Due to the increased attention given to citation-based indicators, scholars discuss differences in citation patterns across the fields of science and various disciplines. As shown in (Glanzel \& Schoepflin, 1995; de Bellis 2009), the ageing of publications in social sciences and humanities (SSH) is slower than in natural sciences. Thus, Wang (2013) showed that for SSH journals optimal citation windows go between 5 and 15 years, shorter or longer periods do not allow for tracking publication influence. The literature agrees (Glanzel \& Schoepflin, 1995), that threeyear citation windows help to balance fields rapidly becoming obsolete (e.g. mathematics, chemistry, physics) and the fields that become obsolete more slowly (e.g. humanities and social sciences). The current study attempts to cover both types of citation behavior ('early rise and sharp decline' and 'late rise and slow decline') among publications in SSH. Therefore, longer citation windows were used.

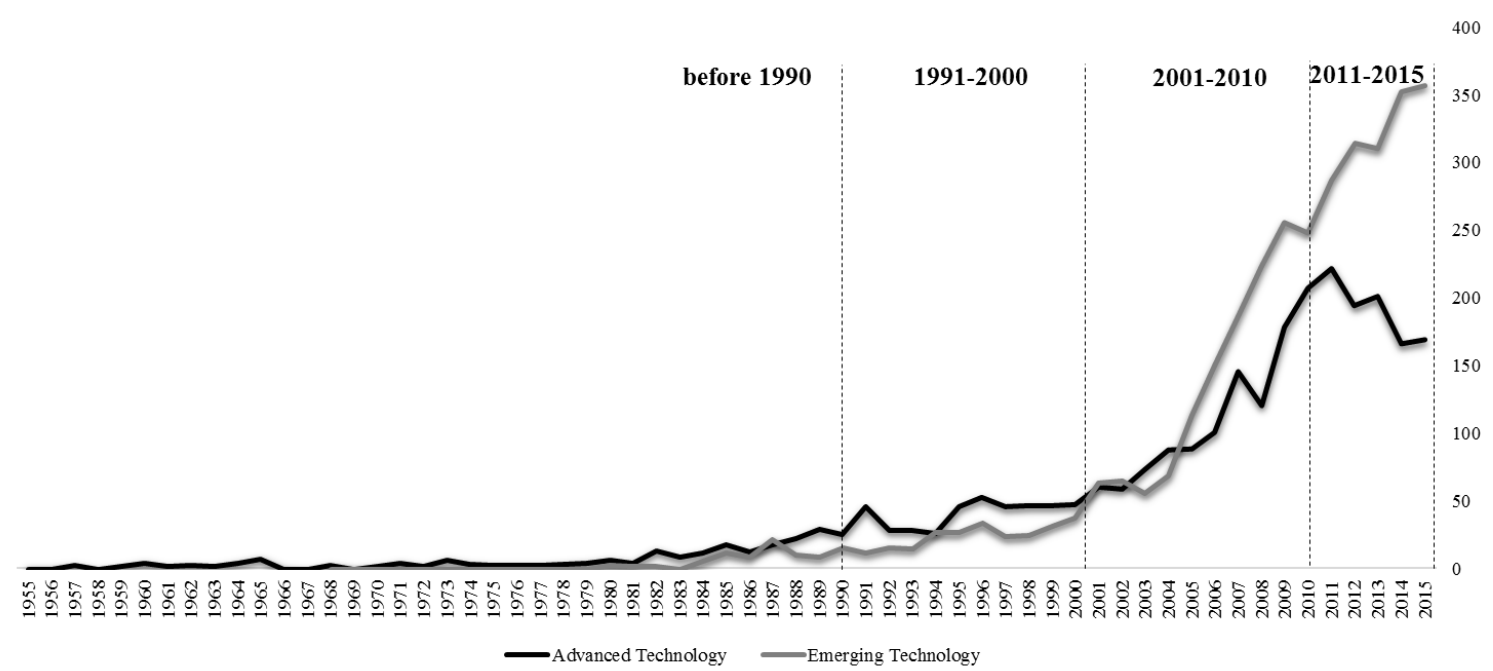

Fig. 3. The number of documents in SCOPUS on advanced technology and emerging technology published in social sciences and humanities sources: $1955-2015$

As the most active growth took place during 1990-2010, these 20 years of active development were divided into two 10-year periods. The remaining years (2011-2015) made up the final period. Finally, we obtained four resulting periods ranging from 35 years to 5 years. Publications on advanced and emerging technologies have differed to various extents during 1955-2015. Despite that, the decision was made to keep the periods the same for both groups of technologies to assure comparability.

\section{Construction of co-citation networks.}

In a third step, VOSviewer version 1.6.5 (van Eck \& Waltman, 2010) ${ }^{1}$ was used to construct cocitation networks (full-counting algorithm). Due to the low density of both networks papers cited at least twice were taken for further consideration. Table 2 provides details about the networks. Betweenness centrality was further calculated in UCINET (Borgatti et al., 2013).

4. Identification of papers co-cited in more than one period.

\footnotetext{
${ }^{1}$ VOSviewer is open-access software for mapping bibliometric data available at: http://www.vosviewer.com.
} 
Following the recommendations provided in Yan and Ding (2009), networks characteristics were compared to identify two types of references: those that have high centrality values, and 'transition references' - papers co-cited in more than one period. Identifying such elements in a network signals the existence of continuous research questions that are one of the crucial elements of research field (Cole, 1983).

\section{Comparison of centrality metrics.}

In order to understand the role of transitionary references in co-citation networks for two or more concurrent periods it was suggested to compare their centrality characteristics of which specific attention is to be paid to betwenness centrality. The latter was selected as a key measure to look at the group of authors connected by the shortest paths passing through a vertex. Compared to other metrics (e.g. degree centrality, Eigenvector centrality or Katz centrality), these centrality characteristics may be applied to any collection of entities with reciprocal quotations and references. It assigns a numerical weighting to each element of a linked set of documents with the purpose of measuring its relative importance within the set. Betwenness centrality characterizes gatekeeping papers (Leydesdorff, 2007; Borgatti \& Everett, 2009) that are given priority attention in this study. Other commonly used metrics such as degree centrality and closeness are considered to provide additional characteristics of the core elements.

\section{RESULTS}

Following the proposed strategy, first the overall publication dynamics was considered. As Fig. 2 shows, the most active period of growth in both areas is observed in the decade from 2001 until 2010. Since 2005 publications on emerging technologies have begun to dominate those on advanced technologies and after 2010 trends go in different directions. While the latter area seems to lose its importance, the former continues to grow at the same rate. The number of papers written in each period for further co-citation analysis is provided in Table 1.

Table 1. Number of papers formed each period

\begin{tabular}{ccc}
\hline Period & Advanced technologies & Emerging technologies \\
\hline Before 1990 & 249 & 95 \\
$1991-2000$ & 418 & 250 \\
$2001-2010$ & 1124 & 1143 \\
$2011-2015$ & 952 & 1620 \\
\hline
\end{tabular}

Before the 1990s, publication sources did not belong to only social or natural sciences (Table 2). As such, 'American Helicopter Society Proceedings', 'Science', 'Rail International', 'European Journal of Operational Research' were primarily sources of information on both areas during the first period. Starting in the second period (1991-2000), a certain differentiation of sources began to take place. While papers on advanced technology were mostly concentrated in natural sciences journals studies, emerging technologies were wider cited among periodicals in social sciences. The identification of sources relevant for both domains such as 'Annual Forum Proceedings American Helicopter Society' indirectly points out that at this stage, advanced and emerging technologies could have been considered similar categories or even synonyms.

Table 2. Top five sources of publications on advanced and emerging technologies

\begin{tabular}{ll|ll}
\hline \multicolumn{1}{c|}{ Advanced technology } & \multicolumn{2}{c}{ Emerging technology } \\
\hline Source & Before 1990 & $\mathrm{N}$ \\
\hline
\end{tabular}




\begin{tabular}{|c|c|c|c|}
\hline \multicolumn{2}{|l|}{ Advanced technology } & \multicolumn{2}{|l|}{ Emerging technology } \\
\hline $\begin{array}{l}\text { Annual Forum Proceedings - American Helicopter } \\
\text { Society }\end{array}$ & 9 & American Journal of Agricultural Economics & 4 \\
\hline Rail International & 4 & $\begin{array}{l}\text { Annual Forum Proceedings - American Helicopter } \\
\text { Society }\end{array}$ & 4 \\
\hline Research Policy & 4 & Science & 4 \\
\hline Science & 4 & European Journal of Operational Research & 3 \\
\hline Technological Forecasting and Social Change & 4 & Technological Forecasting and Social Change & 3 \\
\hline \multicolumn{4}{|c|}{ 1991-2000 } \\
\hline Source & $\mathrm{N}$ & Source & $\mathrm{N}$ \\
\hline $\begin{array}{l}\text { Annual Forum Proceedings - American Helicopter } \\
\text { Society }\end{array}$ & 25 & Technological Forecasting and Social Change & 8 \\
\hline Johns Hopkins APL Technical Digest & 12 & $\begin{array}{l}\text { Annual Forum Proceedings - American Helicopter } \\
\text { Society }\end{array}$ & 5 \\
\hline Journal of Technology Transfer & 7 & International Journal of Technology Management & 4 \\
\hline Research Policy & 5 & Journal of Research on Computing in Education & 4 \\
\hline Textile Outlook International & 5 & American Journal of Agricultural Economics & 3 \\
\hline \multicolumn{4}{|c|}{ 2001-2010 } \\
\hline Source & $\mathrm{N}$ & Source & $\mathrm{N}$ \\
\hline Nature & 19 & $\begin{array}{l}\text { Australian Journal of Emerging Technologies and } \\
\text { Society }\end{array}$ & $\begin{array}{l}3 \\
7\end{array}$ \\
\hline Electronic Engineering Times & 14 & Technological Forecasting and Social Change & $\begin{array}{l}2 \\
9\end{array}$ \\
\hline Pakistan Textile Journal & 13 & $\begin{array}{l}\text { IFIP Advances in Information and Communication } \\
\text { Technology }\end{array}$ & $\begin{array}{l}1 \\
8\end{array}$ \\
\hline Science & 12 & $\begin{array}{l}\text { Portland International Center for Management of } \\
\text { Engineering and Technology Proceedings }\end{array}$ & $\begin{array}{l}1 \\
8\end{array}$ \\
\hline Nonwovens Industry & 10 & $\begin{array}{l}\text { Portland International Conference on Management } \\
\text { of Engineering and Technology }\end{array}$ & $\begin{array}{l}1 \\
5\end{array}$ \\
\hline \multicolumn{4}{|c|}{$2011-2016$} \\
\hline Source & $\mathrm{N}$ & Source & $\mathrm{N}$ \\
\hline Nature & 40 & Technological Forecasting and Social Change & $\begin{array}{l}5 \\
1\end{array}$ \\
\hline Science & 28 & $\begin{array}{l}\text { Proceedings of Portland International Center for } \\
\text { Management of Engineering and Technology: } \\
\text { Technology Management for Emerging } \\
\text { Technologies, } 2012\end{array}$ & $\begin{array}{l}2 \\
5\end{array}$ \\
\hline $\begin{array}{l}\text { IFIP Advances in Information and Communication } \\
\text { Technology }\end{array}$ & 8 & NanoEthics & $\begin{array}{l}2 \\
2\end{array}$ \\
\hline $\begin{array}{l}\text { Proceedings of the International Conference on } \\
\text { Computers and Advanced Technology in } \\
\text { Education, } 2012\end{array}$ & 8 & Scientometrics & $\begin{array}{l}2 \\
0\end{array}$ \\
\hline Scientific Reports & 8 & British Journal of Educational Technology & $\begin{array}{l}1 \\
8 \\
\end{array}$ \\
\hline
\end{tabular}

Multidisciplinary journals such as 'Nature' and 'Science' became the primary publication sources for advanced technology studies after 2000, while emerging technology studies were concentrated either in the conference proceedings of engineering sciences or in management journals. The overall use of the term 'emerging technology' is higher across social sciences discourse while the term 'advanced technology' is better established in natural and engineering sciences journals.

In order to identify existence of a communication core in each of the subsets of data, eight cocitation networks were constructed (Table 3). Both fields, as expected, produced a significant rise 
in the number of references during 2000-2010, however the 'emerging technology' co-citation network outnumbered 'advanced technology' by almost 6 times.

Table 3. Parameters of co-citation networks

\begin{tabular}{ccccccc}
\hline N & Period & Threshold & $\begin{array}{c}\text { Advanced technologies } \\
\text { Number of } \\
\text { references }\end{array}$ & $\begin{array}{c}\text { Emerging technologies } \\
\text { Connected } \\
\text { nodes }\end{array}$ & $\begin{array}{c}\text { Number of } \\
\text { references }\end{array}$ & $\begin{array}{c}\text { Connected } \\
\text { nodes }\end{array}$ \\
\hline 1 & before 1990 & 2 & 2428 & 6 & 1293 & 14 \\
2 & $1991-2000$ & 2 & 6991 & 27 & 5075 & 9 \\
5 & $2001-2010$ & 2 & 22612 & 106 & 38446 & 597 \\
6 & $2011-2015$ & 2 & 34695 & 143 & 68047 & 1260 \\
\hline
\end{tabular}

The co-citation networks of the two technological areas had not differed significantly from the perspective of networks metrics (Table 4 and Appendix 1). For all periods discussions on emerging technology demonstrate higher growth of intensity of communications. However, the density of a network that characterizes the speed at which information diffuses among the nodes as well as the extent to which actors have high levels of constraint is higher for advanced technology networks in all of the considered periods. While for the earlier periods (before 1990 and in 1991-2000) this can be explained by a lower number of papers and therefore tighter communication in cliques, higher density of co-citations in advanced technology against other parameters of the network indicates a slower growth rate and poorer penetration in a wider range of discussions. Established once in the last decade of the twentieth century, this area of research seems to remain constrained from further integration into the agenda of social sciences.

Table 4. Network characteristics of advanced and emerging technology co-citation networks

\begin{tabular}{|c|c|c|c|c|}
\hline \multicolumn{5}{|c|}{$\begin{array}{r}\text { Before } 1990 \\
\end{array}$} \\
\hline & Number of nodes & $\begin{array}{c}\text { Number of } \\
\text { clusters }\end{array}$ & Average degree & Density \\
\hline Advanced technology & 6 & 1 & 5 & 1 \\
\hline Emerging technology & 14 & 1 & 13 & 1 \\
\hline \multicolumn{5}{|c|}{ 1991-2000 } \\
\hline & Number of nodes & $\begin{array}{c}\text { Number of } \\
\text { clusters }\end{array}$ & Average degree & Density \\
\hline Advanced technology & 27 & 2 & 26 & 1 \\
\hline Emerging technology & 9 & 3 & 3 & 0.39 \\
\hline \multicolumn{5}{|c|}{$2001-2010$} \\
\hline & Number of nodes & $\begin{array}{c}\text { Number of } \\
\text { clusters }\end{array}$ & Average degree & Density \\
\hline Advanced technology & 106 & 8 & 10 & 0.1 \\
\hline Emerging technology & 597 & 15 & 22 & 0.03 \\
\hline \multicolumn{5}{|c|}{$2011-2015$} \\
\hline & Number of nodes & $\begin{array}{c}\text { Number of } \\
\text { clusters }\end{array}$ & Average degree & Density \\
\hline Advanced technology & 143 & 6 & 20 & 0.14 \\
\hline Emerging technology & 1260 & 15 & 25 & 0.02 \\
\hline
\end{tabular}

Since the primary intention of this paper was to assess the evolution of the academic discussion about advanced and emerging technologies, the authors focused on the similarities and differences of the knowledge base between concurrent periods. This allowed for tracking the dynamics of network structures, including the identification of key actors and therefore sets of problems connecting discussions about emerging and advanced technologies. Table 5 describes 
the dynamics of co-citation networks: rows indicate periods from which references move, while columns show the ones to which they move.

Table 5. Dynamics of references among periods: rows indicate periods from which references move, columns - the ones to which reference move

\begin{tabular}{llllllllll}
\hline & \multicolumn{3}{c}{ Advanced technology } & & \multicolumn{4}{c}{ Emerging technology } \\
\cline { 2 - 7 } period & 1 & 2 & 3 & 4 & & 1 & 2 & 3 & 4 \\
\hline 1 & - & $\mathbf{0}$ & 0 & 0 & & - & $\mathbf{0}$ & 0 & 0 \\
2 & & - & $\mathbf{0}$ & 0 & & & - & $\mathbf{5}$ & 2 \\
3 & & & - & $\mathbf{6}$ & & & & - & $\mathbf{5 7}$ \\
\hline
\end{tabular}

The area of emerging technology studies demonstrates a higher number of transitionary references. Moreover, the number of such references for the two decades increased by more than 10 times, which confirms the previous observations on better penetration of this area within the social sciences discourse. Five references from the emerging technology co-citation networks moving from 1991-2000 to 2001-2015 include three papers that conceptualize technological evolution in economic terms (Dosi, 1982; Tushman \& Anderson, 1986; Anderson \& Tushman, 1990) and two works on the dynamics of innovation (von Hippel, 1988; Utterback, 1994).

Studies cited both in 2001-2010 and 2011-2015 were focused on a variety of areas. Authors wrote about the various aspects of technological development, including questions concerning the philosophy of science and technology (Latour, 1987; Beck, 1992), technology acceptance (Davis, et al., 1989; Venkatesh \& Davis, 2000), innovation development (Teece, 1986; von Hippel, 1988; Cohen and Levinthal, 1990; Malerba, 2002), approaches to technology forecasting (Daim, et al., 2006), public perception of technology (Slovic \& Weber, 2002; Cobb \& Macoubrie, 2004), and specifically nanotechnology acceptance (Bainbridge, 2002; Bowman \& Hogde, 2006; Scheufele \& Lewenstein, 2005; Renn \& Roco, 2006).

Out of the six references moving from 1991-2000 to 2001-2015 in the co-citation network of advanced technology three coincide with the transitionary references in the emerging technology network of the same period (Teece, 1986; von Hippel, 1988; Cohen and Levinthal, 1990), three others refer to the critical analysis of innovation typology (Garcia \& Calantone, 2002), reflections on knowledge development of a firm (Grant, 1996) and the problem of international technology diffusion (Keller, 2004).

Descriptive statistics and centrality values have not shown a significant difference between the two analyzed technology areas. The majority of references were cited from two to three times (Appendix 1) with no substantial discrepancy between minimum and maximum number of citations. Betweenness centrality values as well as other centrality metrics taken into account did not affect the referencing of papers in the two concurrent periods. As Figure 4 shows, centrality values are distributed more or less equally for stable and transitionary references. Therefore, referring to a paper during a longer period is not related to social networks properties (no statistically significant difference in centrality characteristics for transitionary and stable references were identified).

Betweenness centrality 


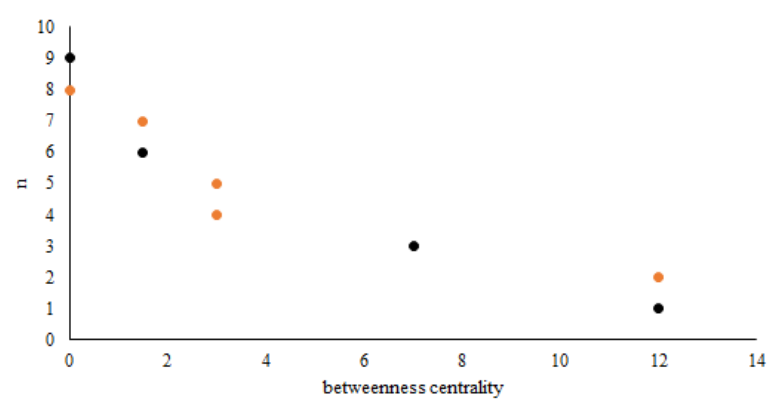

- stable references - transitionary references

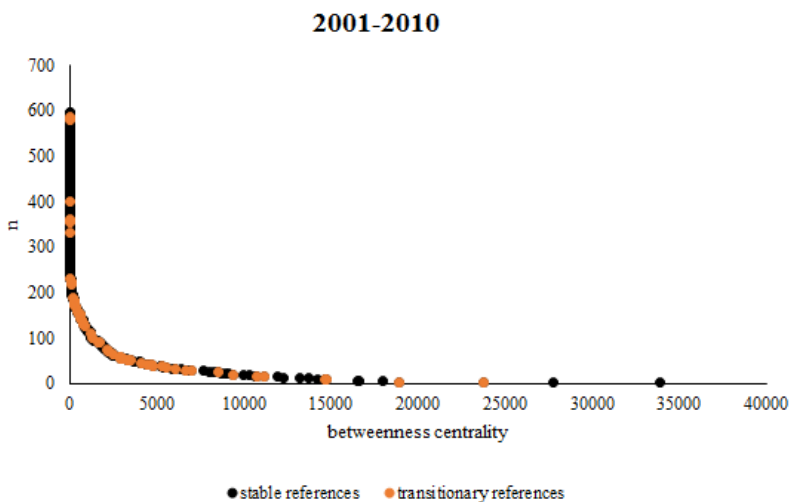

Degree centrality
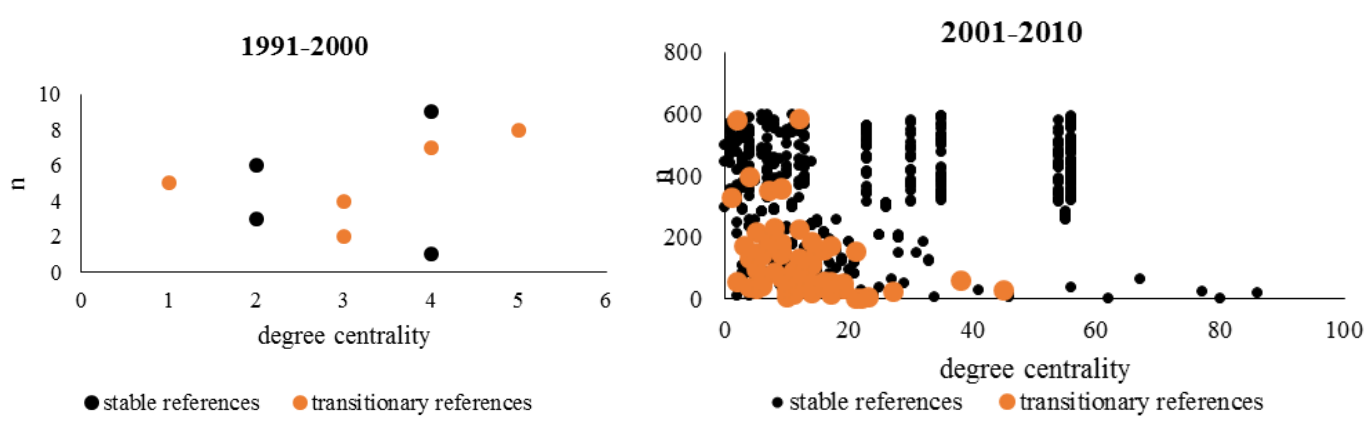

Closeness
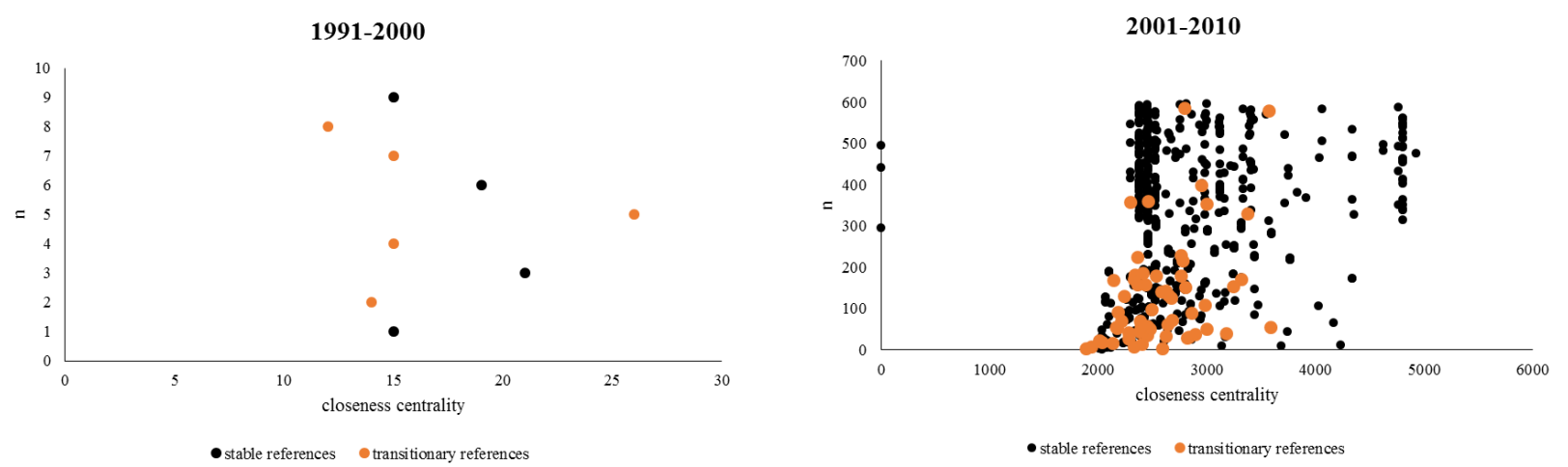

Fig. 4. Centrality metrics of stable and transitionary references for emerging technologies cocitation networks

As seen from the contents of papers appearing in two concurrent periods, both in the case of advanced and emerging technologies, authors refer to studies addressing a wide range of problems concerning technological and innovative development starting from general philosophical issues to more narrowly focused questions concerning the adoption of specific technologies. Although one can see slightly better dynamics in core papers that inspired discussions on emerging technologies, this can hardly be associated with their gatekeeping position in co-citation networks. Moreover, other centrality metrics do not demonstrate any significant difference between transitionary and stable references. The latter means a coincidental use of both concepts and therefore the natural variety of their use in the literature. All of this 
demonstrates that discussions on advanced and emerging technologies can hardly be considered separate research fields. In both cases, one can observe stochastic referencing or its synthesis in relation to a specific problem with which a group of technologies with some common, but abstract characteristics (such as fast growth or radical novelty) can be associated.

\section{CONCLUSIONS}

New technologies are crucial for national economic growth and the improvement of our daily lives. In order to better understand the effects of technology implementation, reveal technological trends and manage technology growth, new developments require proper assessment and monitoring. However, as it was shown, the boundaries of the concept of 'technology' especially when it is connected with some advancements are vague, which leads to difficulties in measurements and increases confusion among decision makers.

The paper presented the evolution of academic discussions concerning two groups of technologies namely 'advanced' and 'emerging', which were identified through the analysis of transitionary references in co-citation networks for several decades throughout the overall period from 1955 to 2015. This allowed for the identification of key alterations in the professional discourse in social sciences about these groups of technologies in order to assure their development as separate research fields.

It was shown that conceptual framing of both concepts is a stochastic process and that social studies in related areas can hardly constitute separate research fields. Papers on advanced technology, though addressing social issues, have a stronger connection with natural sciences while studies in emerging technologies demonstrate a wider penetration among periodicals in social sciences journals. A further analysis of co-citation networks pointed to a lack of common background for advanced technology papers in almost all of the observed periods, only those which were cognitively connected through a limited number of transitionary references. Studies in emerging technologies demonstrated a better consistency in terms of reproduction of citations in related co-citation networks. In particular, three connected periods were identified for which the number of transitionary references was growing. Despite this, centrality characteristics of such references as well as other characteristics of co-citation networks can hardly confirm existence of separate research fields of study. Moreover, traditions that feed the current research agenda on emerging technologies are too diverse and weakly connected.

In conclusion, the analysis showed that at the current stage, existing discussions in both areas cannot be considered separate research fields. Though discussions in both areas demonstrate stochastic referencing and lack replicability of co-citation networks, emerging technologies demonstrate the primary attributes of a developing research field. The suggested approach including the identification and measuring of network characteristics of transitionary references can be used for the analysis and predictive modeling of specific technological domains. However, a keyword analysis or advanced text-mining techniques may provide more evidence about the technological content of promising areas. 
Acknowledgements. The research leading to these results was supported by the Ministry of Education and Science of the Russian Federation (project ID: 14.602.21.0017). We thank Prof. Robert Tijssen for his reflections on the initial idea of this study, Prof. Thomas Thurner and Ms. Ekaterina Dyachenko for the fruitful discussions on the discussed issues and two anonymous referees for their critical notes and comments that greatly improved the manuscript. 


\section{References}

Abercrombie, R., Udoeyop, A., \& Schlicher, B. (2012). A study of scientometric methods to identify emerging technologies via modelling of milestones. Scientometrics, 91(2), 327-342.

Anderson, P., \& Tushman, M. L. (1990). Technological discontinuities and dominant designs: A cyclical model of technological change. Administrative Science Quarterly, 35(4), 604-633.

Ault, G. (1968). Engineering mechanisms and materials. Selected technology for electric power industry. In Proceedings of the NASA SP-5057, Cleveland, OH, USA.

Bainbridge, W. (2002). Public attitudes toward nanotechnology. Journal of Nanoparticle Research, 4, 561-570.

Baldwin, J., \& Da Pont, M. (1996). Innovation in Canadian manufacturing enterprises: Survey of innovation and advanced technology 1993. Cat. No. 88-513-XPB, Statistics Canada, Ottawa.

Baldwin, J. R., \& Sabourin, D. (2002). Advanced technology use and firm performance in Canadian manufacturing in the 1990s. Industrial and Corporate Change, 11(4), 761-789.

Bavelas, A. (1948). A mathematical model for group structures. Human Organization, 7, 16-30.

Bavelas, A. (1950). Communication patterns in task oriented groups. Journal of the Acoustical Society of America, 22, 271-282.

Beck, U. (1992). Risk society: Towards a new modernity. London: Sage.

Borgatti, S. P., \& Everett, M. G. (2006). A graph-theoretic perspective on centrality. Social Networks, 28(4), 466-484.

Borgatti, S. P., Everett, M. G., \& Johnson, J. C. (2013). Analyzing social networks. London: Sage.

Bowman, D., \& Hodge, G. (2006). Nanotechnology: Mapping the wild regulatory frontier. Futures, 38, 1060-1073.

Boyer, K., Leong, G., Ward, P., \& Krajewski, L. (1997). Unlocking the potential of advanced manufacturing technologies. Journal of Operations Management, 15, 331-347.

Burt, R. S. (1992). Structural holes. Cambridge, MA: Harvard University Press.

Burt, R. S. (2002). The social capital of structural holes. In M. F. Guillén, R. Collins, P. England, $\&$ M. Russell (Eds.), New directions in economic sociology (pp. 203-247). Thousand Oaks, CA: Sage Foundation.

Cobb, M., \& Macoubrie, J. (2004). Public perceptions about nanotechnology: Risks, benefits and trust. Journal of Nanoparticle Research, 6(4), 395-405.

Cohen, W. M., \& Levinthal, D. A. (1990). Absorptive capacity: A new perspective on learning and innovation. Administrative Science Quarterly, 35(1), 128-152.

Cohen, W., \& Levinthal, D. (1990b). Absorptive capacity: A new perspective on learning and innovation. Administrative Science Quarterly, 35(1), 128-152.

Cole, S. (1983). The hierarchy of the sciences? The American Journal of Sociology, 89, 111-139. 
Daim, T., Rueda, G., Martin, H., \& Gerdsri, P. (2006). Forecasting emerging technologies: Use of bibliometrics and patent analysis. Technological Forecasting and Social Change, 73, 9811012.

Dangayach, G., \& Deshmukh, S. (2004). Advanced manufacturing technologies: Evidences from Indian automobile companies. International Journal of Manufacturing Technology and Management, 6(5), 426-433.

Davis, F., Bagozzi, R., \& Warshaw, P. (1989). User acceptance of computer technology: A comparison of two theoretical models. Management Science, 35(8), 982-1003.

De Bellis, N. (2009). Bibliometrics and citation analysis: From the science citation index to cybermetrics. Lanham, Maryland, Toronto, Plymouth, UK: Scarecrow Press.

Dernis, H., Squicciarini, M., \& de Pinho, R. (2016). Detecting the emergence of technologies and the evolution and co-development trajectories in science (DETECTS): a 'burst'analysis-based approach. The Journal of Technology Transfer, 41(5), 930-960.

DiMaggio, P., \& Powell, W. W. (1983). The iron cage revisited: Collective rationality and institutional isomorphism in organizational fields. American Sociological Review, 48(2), 147160.

Dosi, G. (1982). Technological paradigms and technological trajectories. Research Policy, 11, 147-162.

Fagerberg, J., Fosaas, M., \& Sapprasert, K. (2012a). Innovation: Exploring the knowledge base. Research Policy, 41(7), 1132-1153.

Fagerberg, J., Landström, H., \& Martin, B. R. (2012b). Exploring the emerging knowledge base of 'the knowledge society'. Research Policy, 41(7), 1121-1131.

Fagerberg, J., \& Verspagen, B. (2009). Innovation studies-The emerging structure of a new scientific field. Research Policy, 38(2), 218-233.

Frickel, S., \& Gross, N. (2005). A general theory of scientific/intellectual movements. American Sociological Review, 70(2), 204-232.

Garcia, R., \& Calantone, R. (2002). A critical look at technological innovation typology and innovativeness terminology: A literature review. Journal of Product Innovation Management, 19(2), 110-132.

Glänzel, W. (1996). A bibliometric approach to social sciences. National research performances in 6 selected social science areas, 1990-1992. Scientometrics, 35(3), 291-307.

Glanzel, W., \& Schoepflin, U. (1995). A bibliometric study on ageing and reception processes of scientific literature. Journal of Information Science, 21(1), 37-53.

Gmür, M. (1973). Co-citation analysis and the search for invisible colleges: A methodological evaluation. Scientometrics, 51(1), 27-57.

Gokhberg, L., Fursov, K., Miles, I., \& Perani, G. (2013). Developing and using indicators of emerging and enabling technologies. In F. Gault (Ed.), Handbook of innovation indicators and measurement (pp. 349-380). Cheltenham: Edward Elgar. 
Grant, R. M. (1996). Toward a knowledge-based theory of the firm. Strategic Management Journal, 17(S2), 109-122.

Halaweh, M. (2013). Emerging technology: What is it? Journal of Technology Management and Innovation, 8(3), 108-115.

Hung, S.-C., \& Chu, Y.-Y. (2006). Stimulating new industries from emerging technologies: Challenges for the public sector. Technovation, 26(1), 104-110.

Kadyrova, A., \& Fursov, K. (2016). Evolution of advanced technology studies: Searching for a communication core. In Supplementary proceedings of the 5th international conference on analysis of images, social networks and texts (AIST-SUP 2016), Yekaterinburg, Russia, April 79 (pp. 51-61).

Keller, W. (2004). International technology diffusion. Journal of economic literature, 42(3), 752782.

Latour, B. (1987). Science in action: How to follow scientists and engineers through society. Cambridge: Harvard University Press.

Leavitt, H. (1951). Some effects of communication patterns on group performance. Journal of Abnormal and Social Psychology, 46, 38-50.

Leydesdorff, L. (2007). Betweenness centrality as an indicator of the interdisciplinarity of Scientific Journals. Journal of the American Society for Information Science and Technology, 58(9), 1303-1319.

Malerba, F. (2002). Sectoral systems of innovation and production. Research Policy, 31, 247264.

Manyika J., Chui M., Bughin J., Dobbs R., Bisson P., \& Marrs, A. (2013). Disruptive technologies: Advances that will transform life, business, and the global economy. McKinsey Global Institute. http://www.mckinsey.com/business-functions/digital-mckinsey/ourinsights/disruptive-technologies.

Marshakova-Shaikevich, I. (1973). Sistema svyazey mezhdu documentami, postroennaya na osnove ssylok: po dannym Science citation index. Nauchno-Tehnicheskaya Informatsiya, 2(6), 3-8 (in Russian).

Martin, B. (1995). Foresight in science and technology. Technology Analysis \& Strategic Management, 7(2), 139-168.

Merton, R. (1988). The Matthew effect in science, 2: Cumulative advantage and the symbolism of intellectual property. ISIS, 79(299), 606-623.

Mullins, N. C. (1972). The development of a scientific specialty: The phage group and the origins of molecular biology. Minerva, 10(1), 51-82.

Mullins, N. C. (1973). The development of specialties in social science: The case of ethnomethodology. Science Studies, 3(3), 245-273.

OECD. (1994). Frascati manual 1993: Proposed standard practice for surveys of research and experimental development. Paris: OECD Publishing. 
OECD. (2013). OECD science, technology and industry scoreboard 2013: Innovation for growth. Paris: OECD Publishing.

Porter, A. L., \& Rafols, I. (2009). Is science becoming more interdisciplinary? Measuring and mapping six research fields over time. Scientometrics, 81(3), 719-745.

Porter, A. L., Roessner, J. D., Jin, X.-Y., \& Newman, N. C. (2002). Measuring national emerging technology capabilities. Science and Public Policy, 29(3), 189-200.

Porter, A. L., Youtie, J., Shapira, P., \& Schoeneck, D. J. (2008). Refining search terms for nanotechnology. Journal of Nanoparticle Research, 10(5), 715-728.

Powell, W. W., \& DiMaggio, P. J. (Eds.). (2012). The new institutionalism in organizational analysis. Chicago: University of Chicago Press.

Renn, O., \& Roco, M. (2006). Nanotechnology and the need for risk governance. Journal of Nanoparticle Research, 8, 153-191.

Robinson, A. L. (1974). Energy storage. II. Developing advanced technologies. Science, 184(4139).

Robinson, D., \& Propp, T. (2008). Multi-path mapping for alignment strategies in emerging science and technologies. Technological Forecasting and Social Change, 75(4), 517-538.

Rotolo, D., Hicks, D., \& Martin, B. (2015). What is an emerging technology? Research Policy, 44(10), 1827-1843.

Scheufele, D., \& Lewenstein, B. (2005). The public and nanotechnology: How citizens make sense of emerging technologies. Journal of Nanoparticle Research, 7, 659-667.

Schummer, J. (2004). Multidisciplinarity, interdisciplinarity, and patterns of research collaboration in nanoscience and nanotechnology. Scientometrics, 59(3), 425-465.

Scott, C. (1973). Health care delivery and advanced technology. Science, 180(4039), 1339-1342.

SEC. (2009). Communication from the Commission to the European Parliament, the Council, the European Economic and Social Committee and the committee of the regions. In Preparing for our future: Developing a common strategy for key enabling technologies in the EU (1257). http://eur-lex.europa.eu/legalcontent/EN/TXT/?uri=CELEX:52009DC0512.

Shibata, N., Kajikawa, Y., Takeda, Y., Sakata, I., \& Matsushima, K. (2011). Detecting emerging research fronts in regenerative medicine by the citation network analysis of scientific publications. Technology Forecasting and of Social Change, 78(2), 274-282.

Slovic, P., \& Weber, E. U. (2002). Perception of risk posed by extreme events. The Conference on risk management strategies in an uncertain world, April 12-13, 2002, Palisades, New York, $1-21$.

Small, H. (1973). Co-citation in the scientific literature: A new measure of the relationship between two documents. Journal of the American Society for Information Science, 24(2), 265269.

Small, H. (1999). Visualizing science by citation mapping. Journal of the American Society for Information Science, 50(9), 799-813. 
Small, H. (2004). On the shoulders of Robert Merton: Towards a normative theory of citation. Scientometrics, 60(1), 71-79.

Small, H., Boyack, K. W., \& Klavans, R. (2014). Identifying emerging topics in science and technology. Research Policy, 43(8), 1450-1467.

Smith, S. (1950). Communication pattern and the adaptability of task-oriented groups: An experimental study. Cambridge, MA: Group Networks Laboratory, Research Laboratory of Electronics, Massachusetts Institute of Technology.

Solo, R. (1966). The capacity to assimilate an advanced technology. American Economic Review, 56, 91-97.

Teece, D. (1986). Profiting from technological innovation: Implications for integration, collaboration, licensing and public policy. Research Policy, 15(6), 285-305.

Tushman, M. L., \& Anderson, P. (1986). Technological discontinuities and organizational environments. Administrative Science Quarterly, 31(3), 439-465.

Utterback, J. (1994a). Mastering the dynamics of innovation. Boston: Harvard Business School Press.

Utterback, J. M. (1994b). Mastering the dynamics of innovation: How companies can seize opportunities in the face of technological change. Boston, MA: Harvard Business School Press.

van Eck, N. J., \& Waltman, L. (2010). Software survey: VOSviewer, a computer program for bibliometric mapping. Scientometrics, 84(2), 523-538.

Venables, P. (1962). The colleges of advanced technologies. Chemistry \& Industry, 36, 15961599.

Venkatesh, V., \& Davis, F. D. (2000). A theoretical extension of the technology acceptance model: Four longitudinal field studies. Management Science, 46(2), 186-204.

Von Hippel, E. (1988). The sources of innovation. New York: Oxford University Press.

Wang, J. (2013). Citation time window choice for research impact evaluation. Scientometrics, 94, 851-872.

Wang, L., Notten, A., \& Surpatean, A. (2013). Interdisciplinarity of nano research fields: A keyword mining approach. Scientometrics, 94(3), 877-892.

Wernimont, P., \& Campbell, J. (1968). Signs, samples and criteria. Journal of Applied Psychology, 55(5), 372-376.

Whitley, R. (2000). The intellectual and social organization of the sciences. Oxford University Press on Demand.

Yan, E., \& Ding, Y. (2009). Applying centrality measures to impact analysis: A coauthorship network analysis. Journal of the American Society for Information Science and Technology, 60(10), 2107-2118.

Youssef, M. (1992). Getting to know advanced manufacturing technologies. Industrial Enginerering, 24(2), 40-42. 
Appendix 1. Descriptive statistics of references citation values

Advanced technology

\begin{tabular}{lcccc}
\hline Period & Min & Max & Average & Standard deviation \\
\hline Before 1990 & 2 & 2 & 2.00 & 0 \\
$1991-2010$ & 2 & 3 & 2.07 & 0.26 \\
$2001-2010$ & 2 & 6 & 2.15 & 0.51 \\
$2011-2016$ & 2 & 6 & 2.60 & 1.05 \\
\hline
\end{tabular}

Emerging technology

\begin{tabular}{lcccc}
\hline Period & Min & Max & Average & Standard deviation \\
\hline Before 1990 & 2 & 4 & 2.64 & 0.84 \\
$1991-2010$ & 2 & 2 & 2.00 & 0 \\
$2001-2010$ & 2 & 8 & 2.27 & 0.64 \\
$2011-2016$ & 2 & 8 & 2.40 & 0.8 \\
\hline
\end{tabular}

